\title{
Coccolithophore populations and their contribution to carbonate export during an annual cycle in the Australian sector of the Antarctic zone
}

Andrés S. Rigual Hernández et al.

Correspondence to: Andrés S. Rigual Hernández (arigual@usal.es)

The copyright of individual parts of the supplement might differ from the CC BY 4.0 License. 

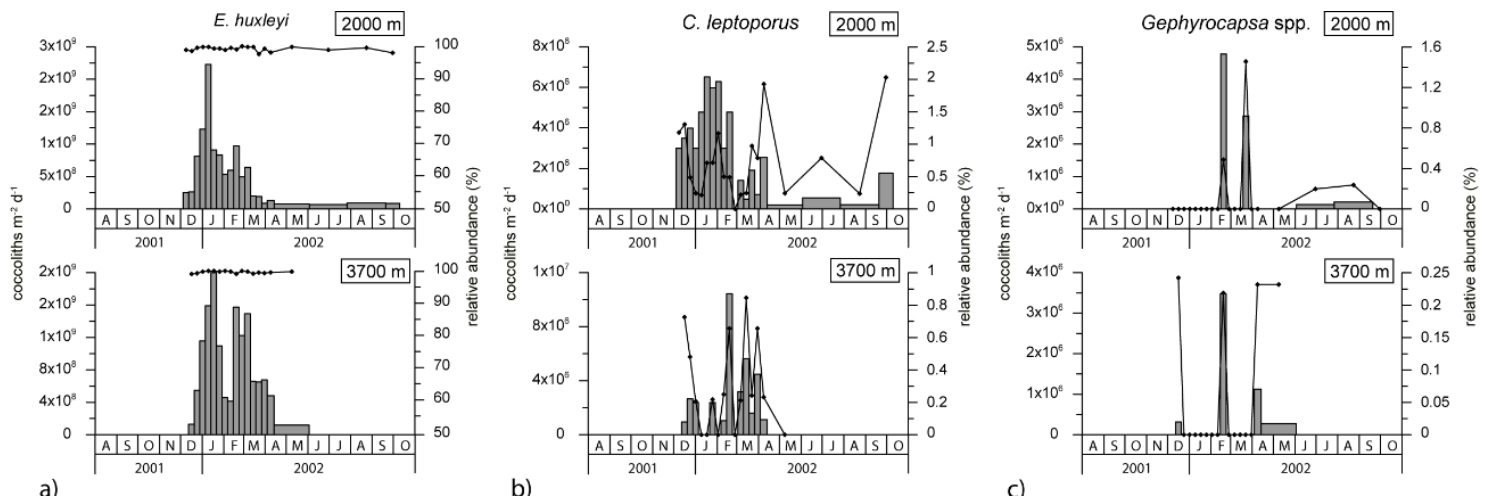

Supplementary figure 1

Supplementary Figure S1: Seasonal variation of flux and relative abundance of the main coccolithophore species captured by the 2000 and 3700 m trap: (a) Emiliania huxleyi, (b) Calcidiscus leptoporus and (c) Gephyrocapsa spp.. 